\title{
NOISE AND VIBRATION OF SPACECRAFT STRUCTURES
}

\section{RUIDO Y VIBRACIÓN DE ESTRUCTURAS DE VEHÍCULOS ESPACIALES}

\author{
Jorge P. Arenas ${ }^{1} \quad$ Ravi N. Margasahayam ${ }^{2}$ \\ Recibido 5 de agosto de 2005, aceptado el 11 de septiembre de 2006 \\ Received: August 5, 2005 Accepted: September 11, 2006
}

\begin{abstract}
RESUMEN
El lanzamiento de los vehículos espaciales genera condiciones extremas, tales como de vibración y acústica, que pueden afectar la torre de lanzamiento, los vehículos espaciales y sus cargas. El ruido en el despegue y durante los dos minutos de ascenso y fase transónica causa intensas cargas acústicas. Estas cargas acústicas son el resultado del intenso medio ambiente acústico generado por la interacción del chorro de salida del motor del cohete y su mezcla con la atmósfera. Los choques pirotécnicos, que ocurren cuando las etapas de un vehículo espacial se separan, causan problemas adicionales de vibración. En este artículo se presenta una revisión de los principales aspectos relacionados con los problemas de ruido y vibración vividos por las estructuras de las naves espaciales. La mayoría de la información está basada en las experiencias con el trasbordador espacial en el Centro Espacial John F. Kennedy (KSC), de la NASA. Además, se presenta una revisión de la investigación en vibroacústica realizada en el KSC. Estos programas de investigación apuntan a diseñar futuras instalaciones de lanzamiento de naves espaciales, en donde los costos y el ruido de los cohetes durante el despegue sean reducidos significativamente.
\end{abstract}

Palabras clave: Ruido y vibración de cohetes, fatiga estructural, trasbordador espacial, vibroacústica.

\section{ABSTRACT}

The launch of space craft generates extreme conditions, such as vibrations and acoustics that can affect the launch pad, space craft, and their payloads. The noise at launch and during the two-minute liftoff and transonic climb phase causes intense acoustic loads. These acoustic loads are the result of an intense acoustic environment generated by the interaction of the rocket-engine exhaust stream mixing with the atmosphere. Pyroshocks, that occur when spacecraft vehicle stages separate, cause additional vibration problems. In this article, an overview of the main aspects related to noise and vibration problems experienced by spacecraft structures is presented. Most of the information is based on the Space Shuttle experiences at the NASA's John F. Kennedy Space Center (KSC). In addition, a review of the vibroacoustic research being conducted at KSC is presented. These research programs are aimed at designing future space launch facilities, where cost and rocket exhaust launch noise are significantly reduced.

Keywords: Rocket noise and vibration, structural fatigue, space shuttle, vibroacoustics.

\section{INTRODUCTION}

Intense acoustic noise and vibration are unavoidable and undesirable by-products generated by the launching of a spacecraft, such as Space Shuttles. The generated noise during firing of rocket engines manifests itself to launch vehicle, sensitive spacecraft and launch pad in the form of airborne acoustics and structure-borne vibration. Therefore, a successful space mission requires thorough consideration of complex sound and vibration interaction of vibroacoustics effects.
The noise and vibration caused by spacecraft rocket engines on launch pads is extremely intense (approximately 180 $\mathrm{dB}$ ) and produces vibration not only of the spacecraft vehicle but also of the launch tower and related support facilities. These vibration levels can be of sufficient magnitude to cause fatigue and eventual failure of some parts. The noise at launch (also during the two-minute liftoff and transonic climb phase through the atmosphere from rocket exhaust and the turbulent boundary layer excitation, separated flows, wake flows and shocks) causes an hostile noise and vibration environment not

\footnotetext{
1 Institute of Acoustics, Universidad Austral de Chile, PO Box 567, Valdivia, Chile, jparenas@uach.cl

2 John F. Kennedy Space Center, NASA, Florida, U.S.A., Ravi.N.Margasahayam@nasa.gov
} 
only for the spacecraft itself but also for the delicate electronics and payload packages aboard [1]. Then, the primary source of structural vibrations and internal loads during launch is due to these acoustic loads. Once the vehicle achieves supersonic speed, the effect of rocket exhaust noise are generally minimal compared with the turbulent flow noise excitation. In addition, pyroshocks and other transients that occur during separation stages can also cause vibration problems. Therefore, being able to manage and suppress these undesirable conditions is critical to proper functioning of vehicle components, payloads, and launch support structures.

The rocket engines produce noise throughout the whole frequency range of interest, but the high frequency content is particularly intense. High frequency noise remains a matter of concern in space vehicles, since during launch it can be enhanced due to deflected jet flow noise and associated acoustical reflections. High frequency noise adds concern because it causes a large number of stress reversals in space vehicles structures, space station payloads, satellites, and electronic packages. These stress reversals can cause fatigue failure during launch and the two-minute flight phase through the atmosphere [1].

The launch environment is characterized as a random, nonstationary and short duration transient. Structural resonance is always present due to wide band excitation inherent in the generated acoustic environment. Thus, prior knowledge of the launch sound and vibration environment is important for defining impact lines (the boundaries beyond which no debris from an uncontrollable rocket will impact the ground) and blast zones (areas created by acoustic and shock propagation waves). Acoustic pressure waves are of concern both in the near field (structures and equipment) and in the far field (wildlife and community) [2].

Because of the unique nature of the launch environment, there is incomplete knowledge within the aerospace industry and the government on the prediction of and structural response to launch environments. The problem is acute for new launch systems prior to first launch and requires design of reusable and survivable launch facilities with mitigating features.

Space launch facilities and space vehicles are complicated structural systems and the sound field is even more so. Large finite element FEM computer programs and codes were developed in the 1960s and 70 s. More recently boundary element BEM programs have been developed as well and some efforts have been made to use coupled $\mathrm{BEM} / \mathrm{FEM}$ programs to predict the forced vibration responses of launch facilities and space vehicles. In addition, empirical methods have been found useful and energy methods such as the Statistical Energy Analysis (SEA) approach are frequently used [3].

The purpose of this article is to provide a brief overview of the main vibroacoustic problems involved during the launching of a spacecraft, mainly focused on the Space Shuttle experience at the NASA's John F. Kennedy Space Center (KSC). The research efforts developed at KSC to reduce acoustic environment at the payload, vehicle and ground systems to lower maintenance costs and environmental impacts are outlined.

\section{VIBROACOUSTIC EFFECTS ON MAN AND STRUCTURES}

\section{Vibroacoustic effects on human body}

The human body is both physically and biologically a system of an extremely complex nature. When regarded as a mechanical system it contains a number of linear as well as non-linear elements, and the mechanical properties are quite different from person to person. Biologically, the situation is by no means simpler, especially when psychological effects are included. In considering the response of man to vibroacoustic excitations it is necessary to take into account both mechanical and psychological effects.

Usually the effects of vibroacoustic sources on human body are though to be related just with hearing loss and discomfort. However, several of the structural sound and vibration spacecraft problems have frequency components that do not affect considerably the ear mechanism.

One of the most important parts of the human body, considered as a mechanical system, corresponds to the thorax-abdomen system. This is due to a distinct resonance effect occurring in the 3 to $6 \mathrm{~Hz}$ range, which makes efficient vibration isolation of a sitting or sanding person very difficult. A further resonance effect is found in the 20 to $30 \mathrm{~Hz}$ region and is caused by the head-neck-shoulder system. In the region of frequencies ranging from 60 to 90 $\mathrm{Hz}$ disturbances are felt which suggest eyeball resonances, and a resonance effect in the lower jaw-skull system has been found between 100 and $200 \mathrm{~Hz}$ [4].

By means of continuous structural methods, which can become very complex, it has been shown that for the skull itself the fundamental mode of vibration is located in the 300 to $400 \mathrm{~Hz}$ region, with resonances for higher 
modes around 600 to $900 \mathrm{~Hz}$. At higher frequencies, wave theory both in the form of shear waves and compressional waves has to be used.

Psychological effects such as perception, discomfort, and pain, have been studied in some detail. Most of the studies have been carried out on vehicle drivers and aircraft pilots, whose ability to perform complex tasks under adverse vibroacoustical conditions, is particularly important. Vibration at frequencies below $1 \mathrm{~Hz}$ occurs in many forms of transport and produces effects, e.g. Kinetosis (motion sickness), which are completely different in character to those produced at higher frequencies [5]. However, these effects cannot be simply related to the intensity, duration, and frequency, as has been possibly in the range from $1 \mathrm{~Hz}$ to $80 \mathrm{~Hz}$. In addition, human reaction to vibration below $1 \mathrm{~Hz}$ is extremely variable and seems to depend on a large number of external factors which have nothing to do with the motion.

Above $80 \mathrm{~Hz}$, the sensations and effects are very dependent upon local conditions at the point of application. These external factors heavily influence the response of the skin and superficial tissue chiefly affected by frequencies above $80 \mathrm{~Hz}$. Despite of this variability and the limited amount of data available, some attempts have been made to formulate tentative standards for whole-body vibration [6]. Exceeding the exposure specified by these standards will cause noticeable fatigue and decreased job proficiency in most tasks. The degree of task interference depends on the subject and the complexity of the task, a matter of high importance for astronauts [7]. Fortunately, astronauts are just subjected to intense vibroacoustic excitation at launch and during the two-minute liftoff and transonic climb phase through the atmosphere (see figure 1). Therefore, the vibroacoustic effects on the spacecraft structures and associated facilities require much more attention both theoretical and experimental.

The appreciation of noise and vibration during the launching of a Space Shuttle starts at the Space Shuttle Main Engines (SSME) ignition. Then, a loud roar and heavy vibrations in the cockpit, described as driving a car down a railroad track, are perceived. This is because the SSME's produce close to a million pounds thrust and the rocket is held to the pad via bolt/nut arrangement. Later, noise and vibration increase significantly when the Solid Rocket Boosters (SRB) are ignited. However, at this stage vibration and noise are not so intense that astronauts cannot read instruments. The communication interference is avoided by means of the use of intercom. Then at and during the lift-off the vibrations steadily increase up to Mach 1, where shock waves add to the shaking. Later, the vibrations moderate as the Shuttle rises into thinner air as it ascends. When SRB's burn out and are separated 2 minutes after lift-off, a dramatic change occurs, marked by a bang due to explosive bolts being fired (pyroshocks) and, thus, noise and vibration end at last.

The SRB separation occurs around 25 miles from ground. The air is very thin there for wind noise or shock waves to shake the astronauts. At this point, even though SSME's are still operating there is virtually no noise or vibrations during the rest of the ascent until external tank (ET) ejection, which occurs around 8.5 minutes after lift-off.

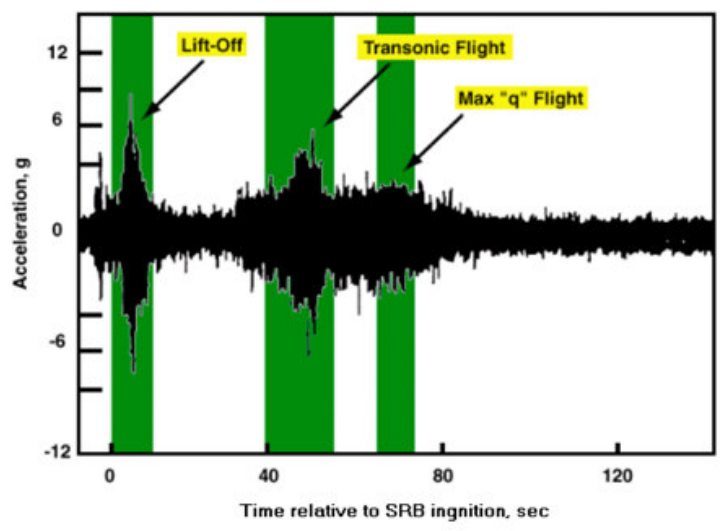

Figure 1. Typical vibration time history during a Space Shuttle launch.

\section{Vibroacoustic effects on structures}

Mechanical Fatigue: In general, failure can be caused by the occurrence of one, or a few, excessive vibration amplitudes or by the fact that a certain vibration amplitude value is exceeded for too great a time. However, mechanical fatigue is having a considerable attention as an important source of structure failure. The fatigue phenomenon is originated from local yield in the material or, in other words, from a sliding of atomic layers [4]. This sliding is caused as a combination of dislocations (irregularities in the crystalline structure of the material) and local stress concentrations. Each slip, no matter how small, is connected with a small deterioration of the material, independent of the direction of the slip. The deterioration stops only when the slip stops. When slip bands have been formed they are, under continuous vibration loading, observed to progress and to form minute cracks which eventually join together and produce major cracks [8]. Even though it is possible to describe a certain part of the fatiguing process by means of some deterministic approaches, both the formation of slip bands and the final crack instability stages are of a highly statistical nature [9]. 
Mean stress: the stress which causes a failure is usually composed of at least two major components: a mean stress and a varying stress superimposed upon it. Classical theoretical methods for modeling this failure stress assume a sinusoidal variation about a constant mean stress [4]. For the case of a random signal varying about a mean stress, the problems associated with the randomness of the signal and those associated with the steady stress can be considered to be independent of each other. Then, the randomly fluctuating component is reduced to an equivalent sinusoidal stress giving the same fatigue life and the classical theoretical models can be used to give an estimate of the lifetime of the structure [9].

Acoustic fatigue: corresponds to the failure of structures excited by direct acoustic radiation (acoustic load), rather than by structure-borne vibration. Evidently, the problem has been most acute in aerospace structures where acoustic loading is caused both by direct radiation from the power plant and by the generation of intense acoustic disturbances in the boundary layer during high speed flight. For many rocket components, the acoustic fatigue requirements, and not the static strength requirements, determine the design of the structure. Some parts of the airframe fall on the line of maximum radiation of a jet exhaust, which is highly directional and has maximum intensity at angles of between $30^{\circ}$ and $45^{\circ}$. Figure 2 shows the noise sources of a supersonic jet. During the Space Shuttle lift-off turbulent eddies created due to mixing of hot gases with ambient air lead to shock, which is the strongest source of noise.

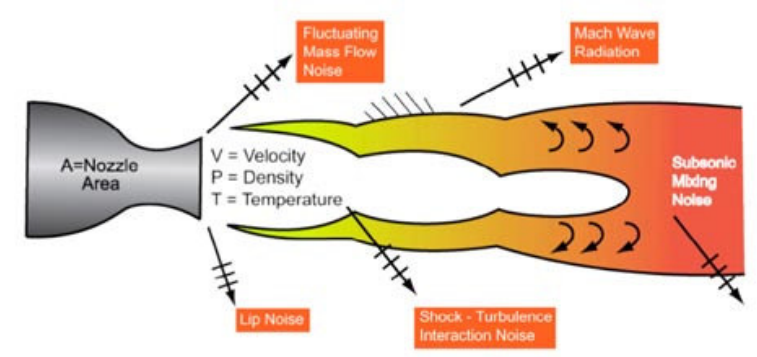

Figure 2. Supersonic jet exhausts noise sources.

In addition to the case of engine exhaust and nacelle components, trailing edge wing panels and rear fuselage panels are often seriously affected. As the total acoustic power radiated by a jet exhaust is proportional to the eight power of the jet efflux velocity (between the cube and the fifth power of the jet efflux velocity for rockets, see figure 3 ), and the square of the jet diameter, the magnitude of the acoustic fatigue problem during the launching of a spacecraft can be readily appreciated.

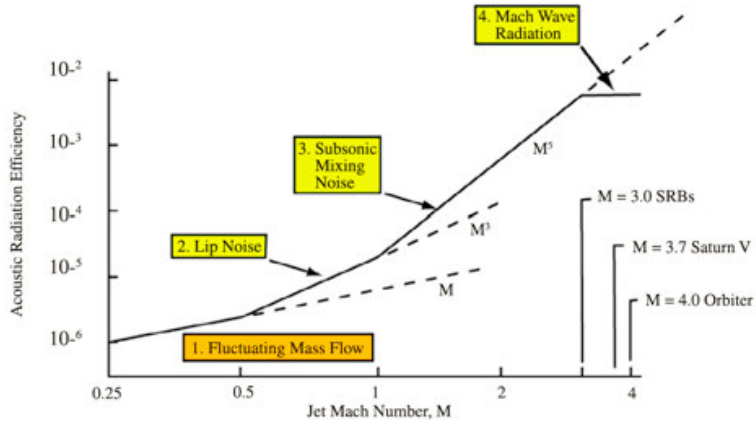

Figure 3. Acoustic radiation efficiency of noise sources in the jet exhaust.

The incident acoustic wave generates various modes of vibration in a structure, causing the stress concentrations which lead to eventual failure. This consideration is particularly important to avoid damage to the payload.

Shock and Transients: a shock is characterized by a sudden occurrence and a short duration in relation to the natural frequency of the structure on which the shock is acting. A transient, however, may last for a time which corresponds to several cycles at the natural frequency of the structure. Both phenomena produce a rapid transfer of energy, which is characterized by the length, rise time, and specific form of the shock pulse [4]. In general, the shock response spectrum is used to compare shock motions, to formulate laboratory tests, and to design structures to withstand shock inputs. Permanent damage need not necessarily take place for a structural system to fail a shock test, so a simple test of destruction may not always be sufficient to assure survivability. In addition, the characteristics of the shock environment must be known with reasonable accuracy in order to ensure that environmental tests are valid. For this reason, measured time histories are often used as laboratory tests excitations in order to reproduce the actual conditions experienced in use.

Pyrotechnic shock, or pyroshock, is the transient response of a structure to loading induced by the ignition of pyrotechnic (explosive or propellant activated) devices [10]. These devices are typically used to separate structural systems (e.g., separate a spacecraft from a launch vehicle) and deploy appendages (e.g., solar panels). Pyroshock is characterized by high peak acceleration, high-frequency content, and short duration. Because of their high acceleration and high frequency, pyroshock can cause spaceflight hardware to fail. Verifying by tests that spaceflight hardware can withstand the anticipated shock environment is considered essential to mission success. 
In practical cases, the actual mode of failure and time to failure are dominated by the local physical features of the structure as well as external factors such as corrosion, temperature, pre-treatment, etc. The failure of a structure is therefore dominated by the weakest link in the failure chain and much effort is required to identify and eliminate them. Fatigue cracks may begin form stress concentrations at sharp corners, surface irregularities or damage, or welds. Large welded structures in a corrosive environment under the action of continuous random vibroacoustic excitation, such as in the case of spacecraft structures, are particularly susceptible to failures emanating from discontinuities in welds.

On the other hand, acoustic blankets have been used in the payload fairing of expendable launch vehicles to reduce the fairing's interior acoustics and subsequent vibration response of a spacecraft [10]. For example, the Cassini spacecraft (see figure 4), launched on a Titan IV/Centaur in October 1997, required lower acoustic levels in order to avoid an extremely costly vibration requalification of the Cassini's spacecraft on-board electric power source known as the Radioisotope Thermoelectric Generator (RTG). Thus, new acoustic blankets were developed and tested to reach NASA's goal of reducing the Titan IV acoustic environment to allowable levels for the Cassini spacecraft and RTGs [11].

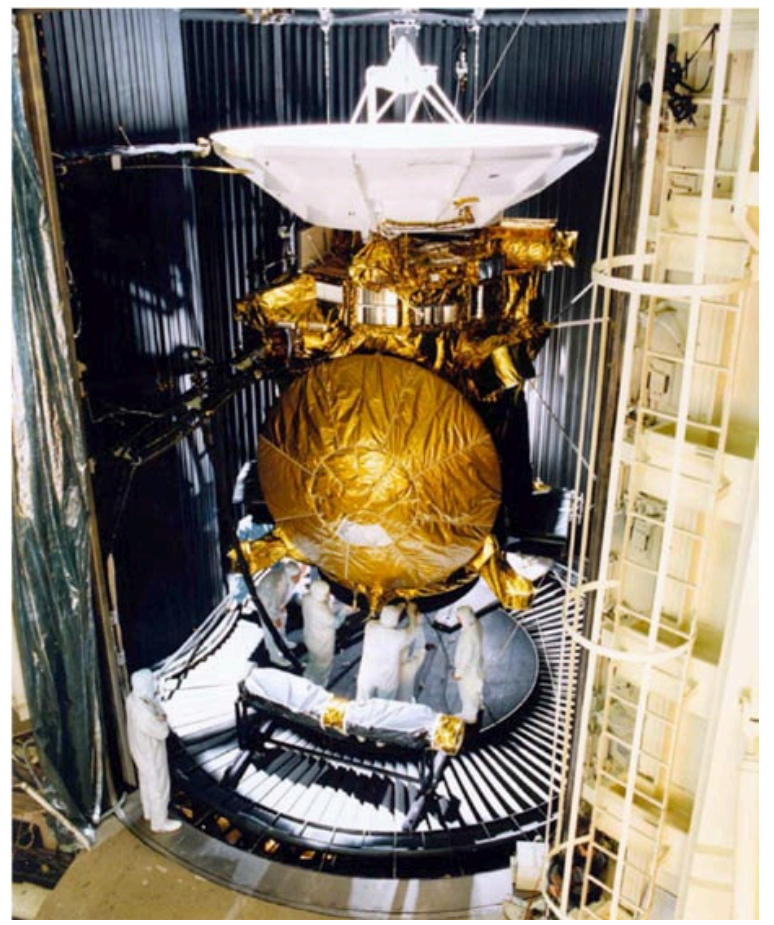

Figure 4. Cassini spacecraft.

\section{LAUNCH PAD VIBROACOUSTICS}

As discussed above, spacecrafts are subjected to a variety of dynamic environments, which may include: quasi-static vibration and acoustic loads at launch, pyrotechnic shocks generated by separation mechanisms, on-orbit jitter, and sometimes, planetary landing loads [12]. Figure 5 shows the launch of a Space Shuttle from NASA's KSC. Given the extend of the jet plume, one can only imagine the severe noise and vibration environment which a spacecraft, launched by the shuttle or by an Expendable Launch Vehicle (ELV), must survive. In particular, the launch pad and ground support equipment and structures in the proximity of the launch pad are subjected to intense acoustic pressures generated by rocket exhausts. Vibroacoustic coupling is a measure of a structure's tendency to vibrate when subjected to acoustic loads. This vibration can lead to degradation of a structure, resulting in increased maintenance costs.

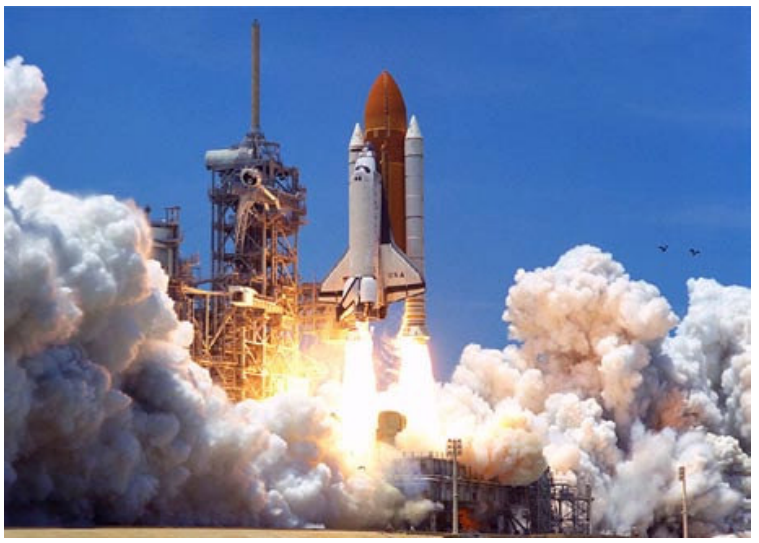

Figure 5. Launch of a space shuttle.

The design of launch pad structures, particularly those having a large area-to-mass ratio, is governed by launchinduced acoustic pressures, which are relatively short transient (less than 20 seconds) with random amplitudes and exhibiting a non-Gaussian distribution. The factors influencing acoustic excitation or forcing on any pad structure are numerous (acoustic efficiency, clustered and homogeneity of rocket engines, varying diameters, launch trajectory, pad placement of structure, atmospheric conditions, shielding, etc.).

The launch pads, second only to the massive Vehicle Assembly Building, are signature features of the NASA's John F. Kennedy Space Center (KSC) landscape. The pads were originally built for the huge Apollo/Saturn V rockets that launched astronauts on their historic journeys to the moon and back (see figure 6). 


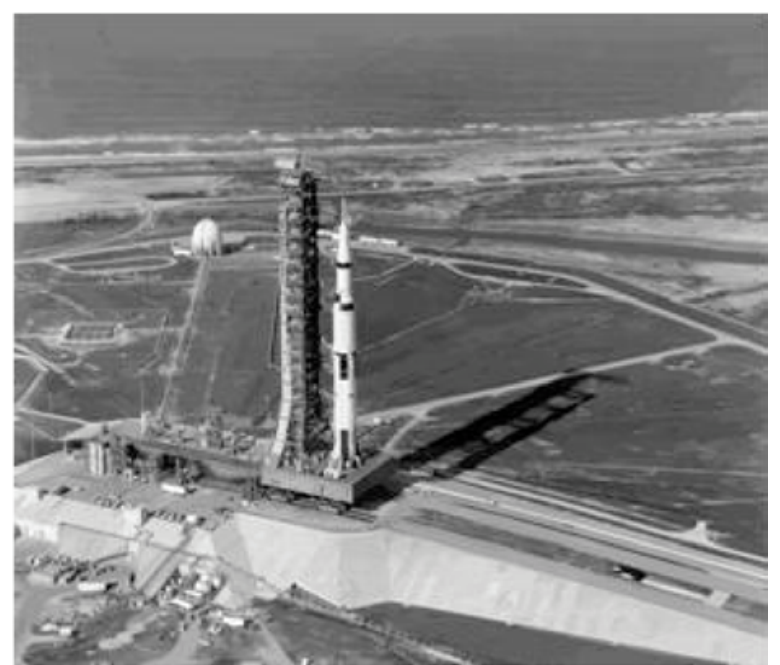

Figure 6. Saturn V on launch pad 39A.

Following the joint U.S.-Soviet Apollo-Soyuz Test Project mission of July 1975, the pads were modified to support Space Shuttle operations (see figure 7). Most significant manned space flight and related endeavors, such as Apollo, Skylab, Apollo-Soyuz, Hubble Space Telescope and the International Space Station, originated there.

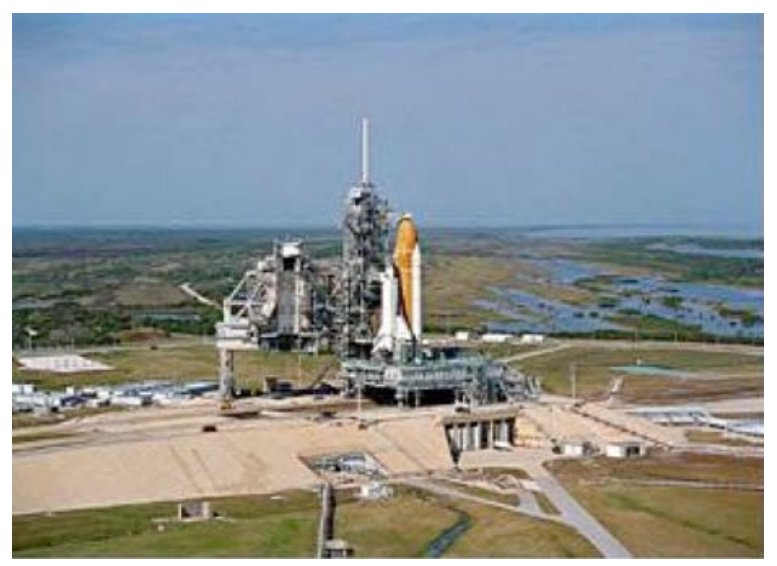

Figure 7. Space shuttle on launch pad 39A.

For the Space Shuttle, two permanent service towers were installed at each pad: the Fixed Service Structure and the Rotating Service Structure. On April 12, 1981, Shuttle operations commenced at Pad A with the launch of Columbia on STS-1 and have continued with over 100 missions. Space Shuttle launches with a 5 to $1 \mathrm{~min}$ launch window (required to service the International Space Station) necessitate all aspects of ground system operation with a high degree of reliability. More than 50 or so launches from each pad mean safety margins of structures are closely scrutinized to ensure structural integrity and avoid costly repairs. Thus, efforts are directed at continual development of methodologies necessary to improve safety in spaceflight hardware, reliability and availability of critical launch pad structures [2].

To far-off observers, the virtually identical $99 \mathrm{~m}$ (325-ft) pads seem to be simple frameworks that support and protect the Space Shuttle before launch; the pads, however, are two of the most complicated and extraordinary structures at KSC. The launch pads A and B were not built to be used decade after decade. Thus, they require continual maintenance, complicated configuring and thorough testing prior to launch. The corrosive air and blazing sun - in addition to the immense forces caused by the rocket propulsion - continue to weather the launch pad structures year after year.

Figure 8 shows a diagram describing the main noise and vibration response of pad structures induced by rocket launch.

\section{Space Shuttle Experience at KSC}

The Space Shuttle approach to the consideration of acoustic loads in structural design was similar to that of Saturn V [13]. Initial acoustic loads were predicted using vehicle power scaling and knowledge of Saturn $\mathrm{V}$ launch measurements. Hurricane wind loads were considered to override acoustic load effects. Shuttle solid rocket boosters resulted in a significant ignition overpressure pulse. Many components were qualified for launch service because they had been previously used on Saturn V, which had greater power. The Saturn $\mathrm{V}$ rocket did not produce this ignition overpressure pulse. While the Saturn V used mobile service towers, the Shuttle uses a permanently mounted fixed service structure (FSS) and a rotating service structure (RSS) on the pad.

Many Shuttle-era pad modifications were driven by the need to facilitate Shuttle hardware access, ease of operation and to protect the Shuttle from the weather on the pad and also at lift-off. It is remarkable that no major facilities or ground support equipment have failed after 100 launches of the Space Shuttle to date. This is a testament to the adequacy of the implemented design methods [14]. Launch pad changes were aimed at ensuring processing timeliness, improving margins of safety and eliminating single failure points in the system wherever possible.

The primary mission objectives of the Space Shuttle's maiden flight (STS-1 in 1981) were to check out the overall system. All major system objectives were met 
and the Shuttle's worthiness as a space vehicle was verified, but post flight inspection revealed that an overpressure pulse had occurred. The SRB's ignition pulse resulted in the loss of 16 heat shield tiles and damage to 148 others. Space Shuttle drift across the mobile launch platform (MLP) resulted in a $9.1 \mathrm{~m}$ long crack on the upper deck. The intense reflected acoustical energy exerted significant force on the wings and control surfaces of the Orbiter.

To alleviate these problems, the water spray system (used to provide water for cooling and sound suppression) was modified to ensure a proper flow rate. That system includes quench nozzles installed on the MLP used to dispense a torrent of water on the MLP upper deck, deflector and MLP exhaust holes. In addition, a series of water bags (see figure 9) were installed across the engine exhaust holes. This provided sufficient water mass to damp the ignition overpressure pulse. The water barrier blocks the path of the reflected pressure wave from boosters, greatly decreasing its intensity.
Accurate, repetitive and statistically significant measurements with hands-on efforts to address operational issues at the Space Shuttle launch pad paved the way for $\mathrm{KSC}$ engineers to understand and characterize acoustic loads for application in design and development. Significant strides have been made to advance the stateof-the-art to analytically characterize random acoustic loads. Rocket noise characterization in the past has used traditional sound pressure level (SPL) and Power Spectral Density (PSD) measurements. At KSC, these have been augmented with newly developed functions like the normalized cross-PSD (NCPSD), coherence $(\mathrm{COH})$, pressure correlation length $(\mathrm{PCL})$, correlated pressure distribution (CPD) and response spectra (RS). These in turn have become descriptors of launch-induced acoustic excitation and used in design and modification of launch pad buildings and structures like the Orbiter Weather Protection Structure (OWPS) [15]. The two methods currently used at KSC in response predictions are designated the direct averaged power spectral density and the normalized pressure spectra load models.

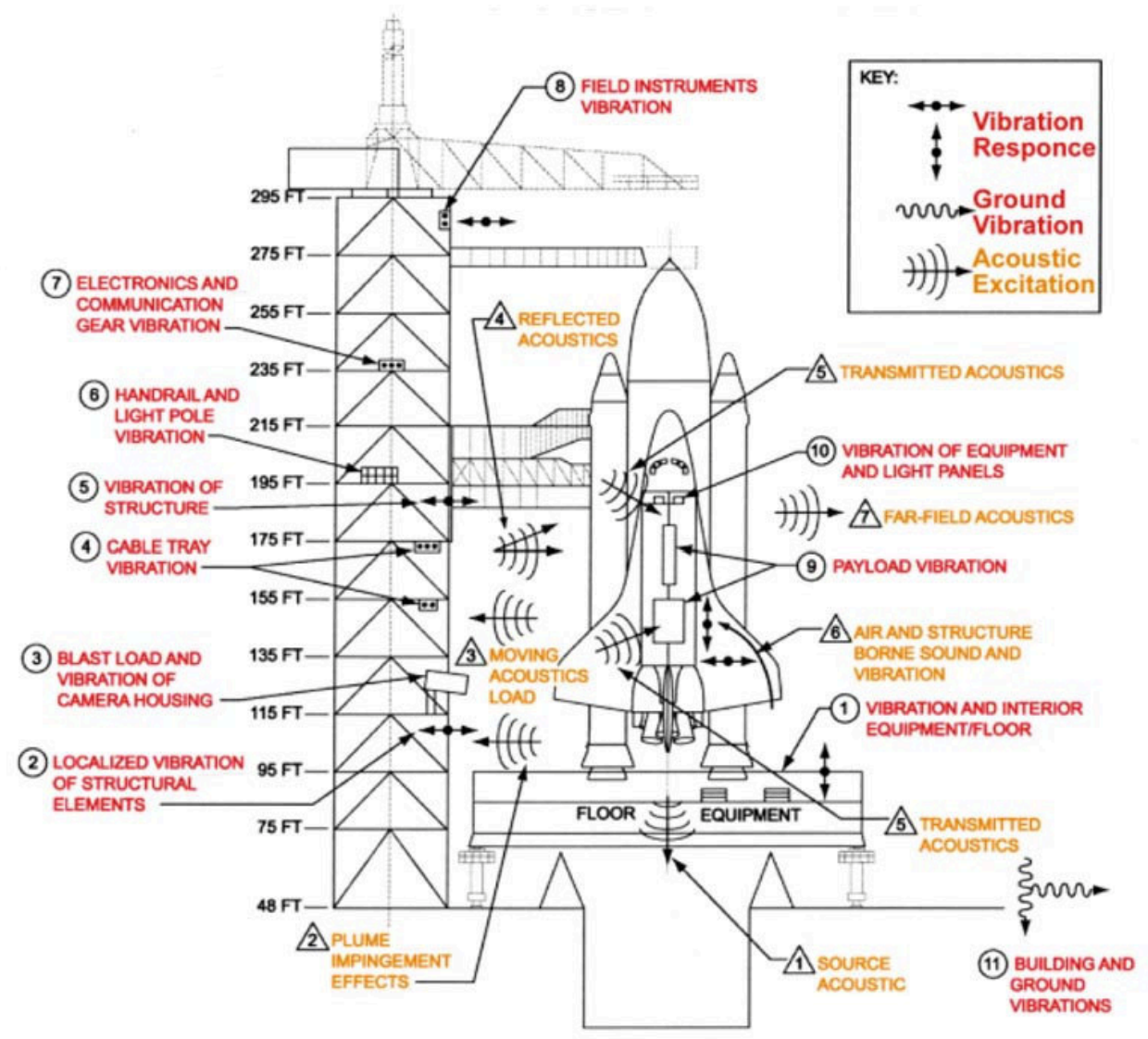

Figure 8. Rocket launch-induced noise and vibration response of structures. 


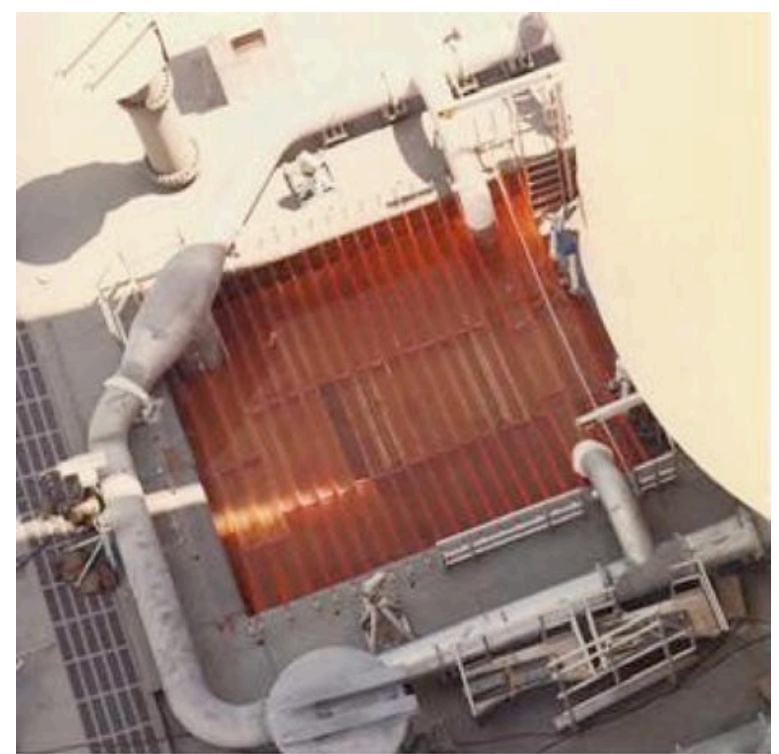

Figure 9. Water bags in SRB exhaust well.

Those two methods were developed at KSC using the knowledge gained from field measurements. The probabilistic method is based on a classical solution of random vibration. It assumes that the acoustic excitation is steady state. The deterministic method on the other hand uses the transient nature of the acoustic excitation. It was specifically developed to address a deficiency in the probabilistic method in the low-frequency regime. It yielded over-predictions in structural responses. These methods are used in the design of structures and equipment when knowledge of both the structure and the excitation is limited. The methods must be sufficiently conservative to provide a reasonable margin of safety. At the same time, the methods must avoid gross over-design and false failure predictions. Measurements on the OWPS (see figures 10 and 11) and other structures facilitated the validation of these analytical models developed for acoustic load consideration in design [16].

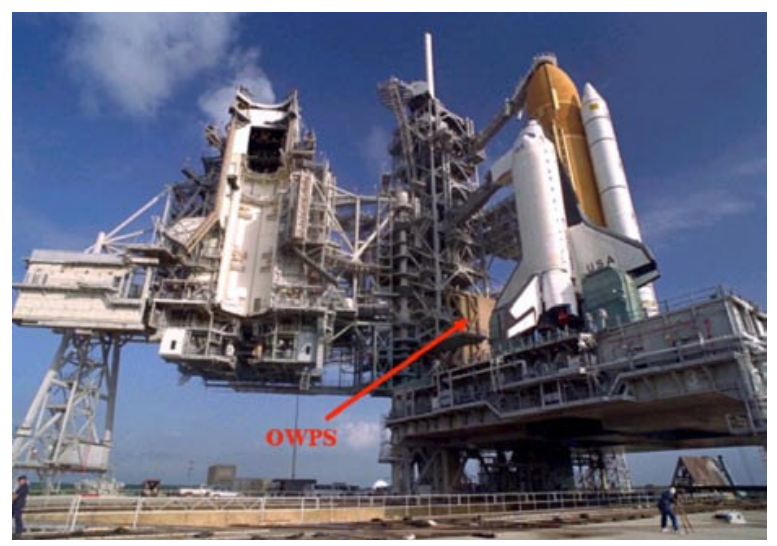

Figure 10. Orbiter weather protection structure.

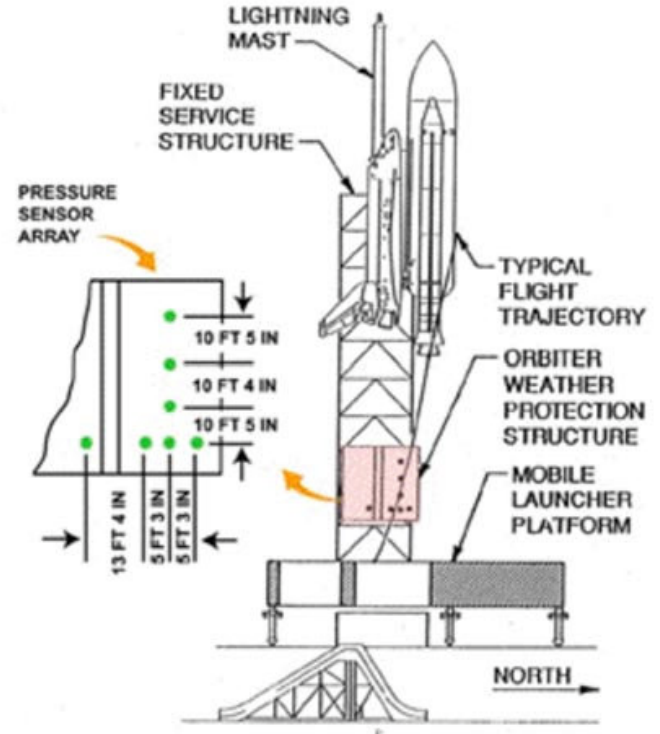

Figure 11. Sensor position for measuring at the OWPS.

\section{Verification Test Article}

Space Shuttle experience has provided the opportunity to measure the launch environment on structures for over 100 launches to date. However, these measurements were not generally suitable for a test-analysis correlation effort. That effort required an array of sensors measuring acoustic excitation and vibration response on the structure simultaneously. Since most pads' structures are launch critical, they are off-limits for use in validation experiments. The pad structures are too large and complex to easily extract modal parameters. An earlier effort on the OWPS was limited to measuring acoustic excitation only. The idea emerged to take a structure simple enough to characterize in the laboratory and expose it to the Shuttle launch environment.

Thus, the Verification Test Article (VETA) project was born. The premise behind the VETA project was to take testing to the field. This totally eliminated the need to simulate the launch environment. A cantilever beam (see figure 12), representative of tall, slender ground structures served as an instrumented test article. It was exposed to acoustic forcing during 8 to 10 Space Shuttle launches. VETA was installed within the pad perimeter $(73 \mathrm{~m}$ from the Shuttle engines), so that the near field rocket noise was characterized and the structural vibration response was assessed [17]. 


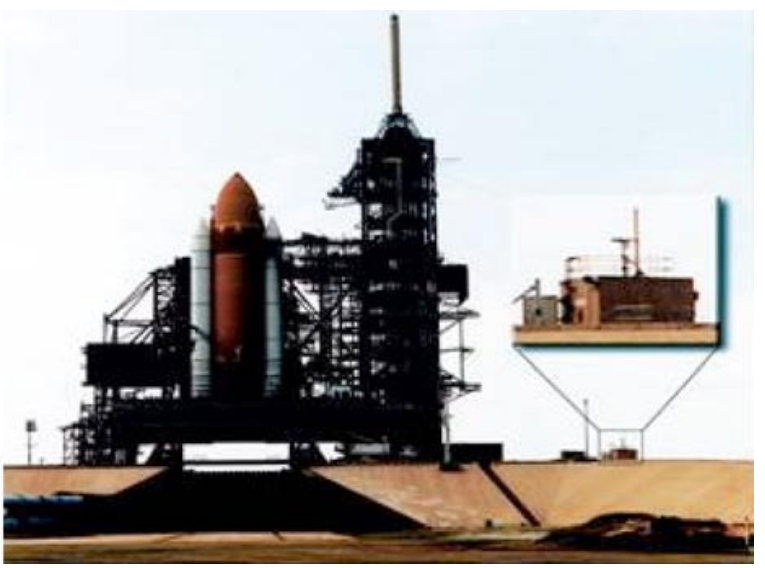

Figure 12. Verification test article on pad 39A.

Microphones were placed lengthwise (direction of Shuttle lift-off) to measure pressure loads on the front and back of the VETA. Simultaneous measurements of vibration and strain responses were made and proved to be crucial for the subsequent test-analysis correlation effort. The ability to tune the VETA dynamic characteristics and thereby simulate pad structures, governed the VETA design, instrumentation and analysis requirements. Since the natural frequency of most pad structures is in the nonaudible range ( 1 to $20 \mathrm{~Hz}$ ), this meant that Statistical Energy Analysis techniques could not be used for test analysis correlation. Acoustic, vibration and strain data acquired during the VETA project were used to validate the two KSC-developed analytical vibroacoustic response methods. The results indicated that there is room for improvement in these methods.

During the course of the VETA testing, a new standalone data acquisition system for simultaneous sound and vibration measurement was developed (see figure 13). Lessons learned from VETA tests also proved valuable in the development of a Launch Systems Testbed at KSC.

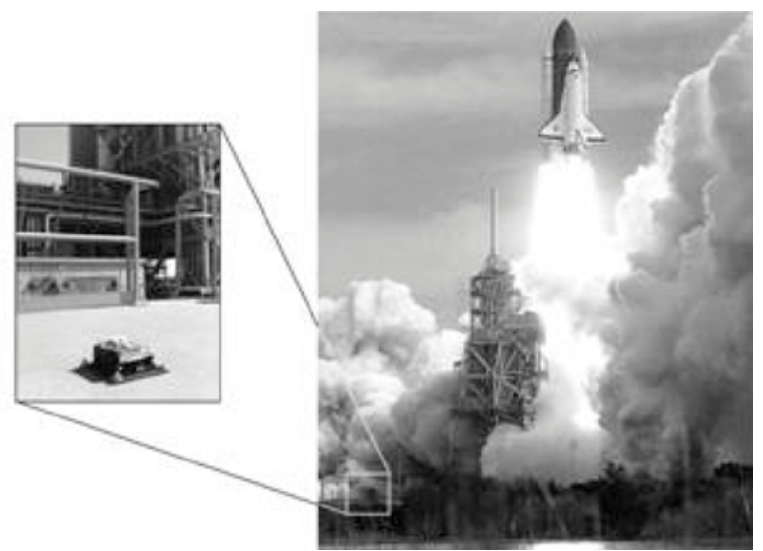

Figure 13. Stand-alone instrumentation.

\section{Launch Systems Testbed}

The Launch Systems Testbed (LST) is aimed at bringing KSC's capabilities under one roof. NASA has designed $\mathrm{KSC}$ as the Center for Excellence for launch and payload processing systems. One key objective of the LST is to simulate nonstationary-scaled launch environments for use in testing and evaluation of launch pad designs for future space vehicles. The end result is to arrive at launch-induced acoustic excitation models that yield more realistic structural vibration response estimates than those provided by the methods currently available. LST projects focus on the following technical areas:

1) Predict, measure, and validate acoustic load models.

2) Enhance structural vibration response methods.

3) Develop acoustic suppression systems without water.

4) Optimize flame trench configurations for new vehicles.

5) Research rocket noise and vibration scaling methodologies.

The newly formed LST is a platform through which KSC will accomplish the above goals. The LST's overall mission is to reduce costs and increase safety, reliability, and availability of launch structures and mechanisms exposed to rocket launch environments. The Trajectory Simulation Mechanism (TSM), a key LST component, is discussed next [18].

\section{Trajectory simulation mechanism}

Shuttle experience, enhancements to available facilities, and the lessons from VETA tests were carefully incorporated in the development stage of the TSM. One drawback of the VETA project was the time factor. To collect statistically significant data required years of testing due to limited Shuttle launches.

Design and development of the TSM capability addressed the problem of acquiring acoustic and vibration data from multiple launches in a short amount of time. Moreover, the TSM is used to generate a nonstationary acoustic load (see figure 14). Thus, a facility to generate scaled launch environments of future vehicles was built.

The TSM simulates varied launch trajectories while inducing nonstationary-scaled random acoustic loads, similar to those generated by the launch of a rocket on test structures and exhaust ducts. The LST projects focus on vibroacoustics, acoustic suppression systems, flame trench optimization and scaling methods. The 
initial capability uses supersonic nitrogen (see figure 15). This will be followed by combusting supersonic jets (see figure 16) at a later stage. The TSM operable life is around 10 years with a usage rate of 1500 simulated rocket launches per year, compared to the Space Shuttle's 7 to 8 launches per year. The TSM allows the placement of exhaust ducts and launch structures under and next to the moving supersonic jet during tests.

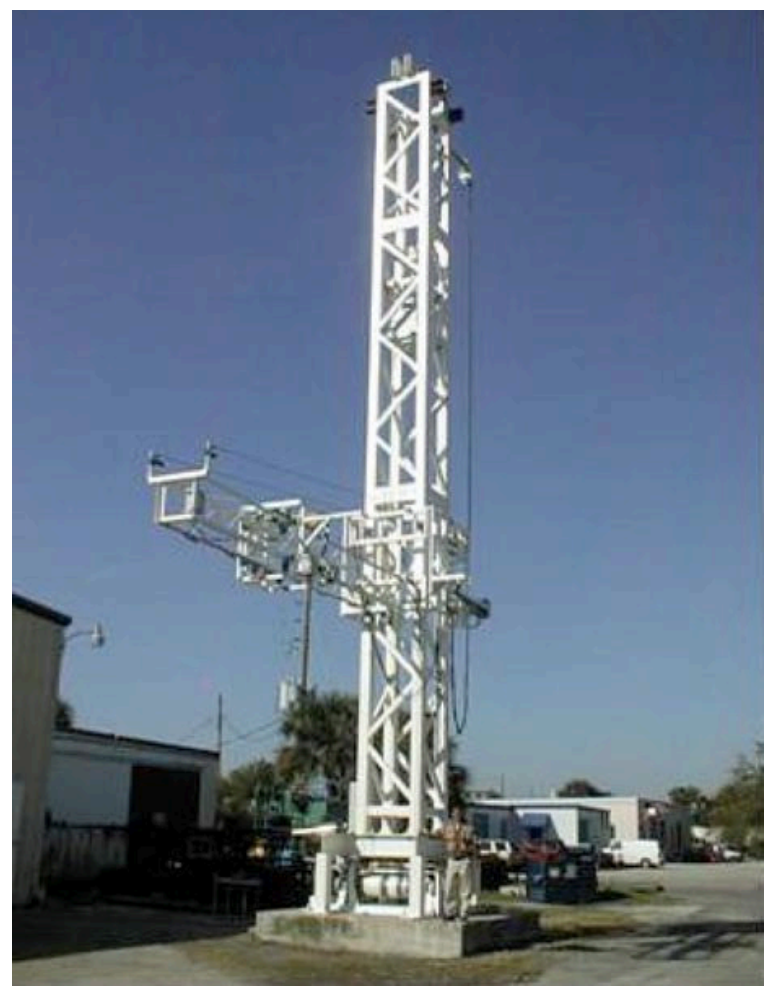

Figure 14. Trajectory simulation mechanism (TSM).

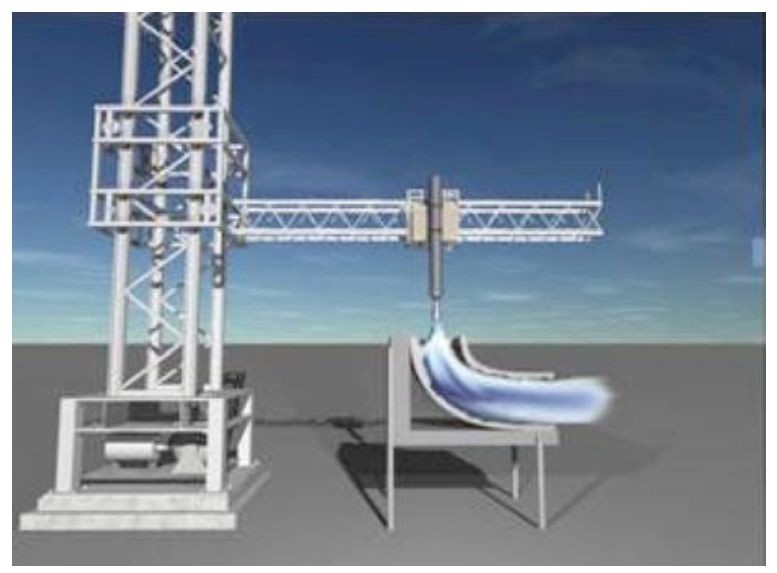

Figure 15. TSM -cold jet with open duct.

The design and development of the TSM capabilities were largely based on US launch industry requirements. The
Space Shuttle will be the mainstay of NASA's fleet for the immediate future. The International Space Station (ISS) goals and objectives drive this use. Therefore, it was decided to scale vertical and horizontal travel based on the Space Shuttle launch scenario. Additionally, requirements for TSM vertical speeds and horizontal speeds were driven by the Space Shuttle trajectory.

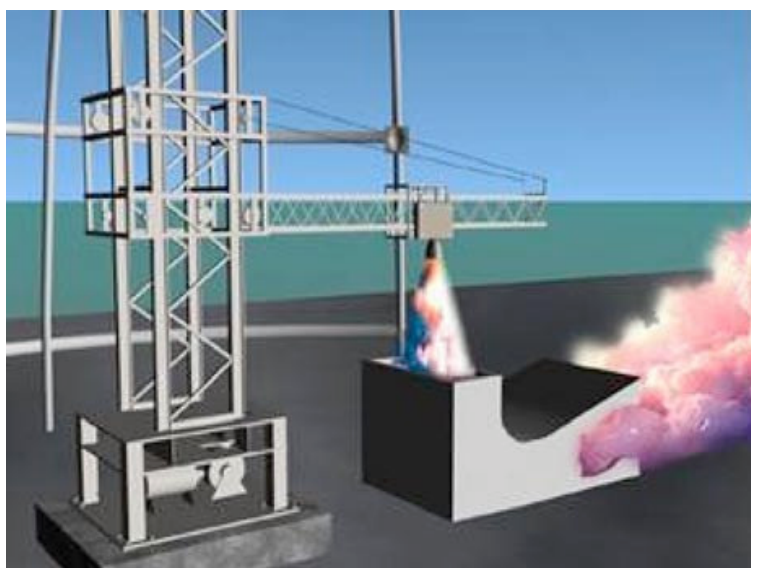

Figure 16. TSM - combusting jet with closed duct.

The travel speeds can be precisely controlled in fractional increments. Thus, based on the above, the scale for the TSM was set at $1 / 10$ the geometric scale of a Shuttle. The TSM has a planar motion capability with a programmable trajectory. In addition to the simulation of a vertical trajectory (similar to Titan, Delta or Atlas vehicles), a trajectory curve up to a third order exponential (see figure 17) can be programmed for the test sequence. This was deemed necessary to simulate the lift-off trajectories of current and future rockets. The TSM allows simulating lift-off rates and it can handle the drift during the lift-off of a rocket as the tower is cleared. The TSM can also allow limited nozzle tilt requirements. Care was taken to minimize flat reflecting surfaces and include weather protection features for outdoor use.

\section{CRAWLER TRANSPORTER VIBROACOUSTICS}

The Crawler Transporter (CT), also known as "the mighty tortoise", is the world's largest tracked vehicle. It weighs 2.7 million $\mathrm{kg}$, is $40 \mathrm{~m}$ long and $34 \mathrm{~m}$ wide. It takes eleven people to drive a single crawler that has a top speed of less than $2 \mathrm{~km} / \mathrm{h}$ when fully loaded. The KSC has two of these massive machines. Figures 18 and 19 show one of them. They were originally designed and built for the Apollo program in the $1960 \mathrm{~s}$, but their function today is to move NASA's Space Shuttles, complete with launch platforms, from the Vehicle Assembly Building to the launch pad. This 5.6 to $8 \mathrm{~km}$ journey takes about 8 hours. 
The United Space Alliance sought outside assistance to evaluate and develop noise control measures for NASA's two CTs at KSC as part of a modernization and upgrading program [19]. The first phase of the sound study encompassed testing and engineering analysis of significant sound sources to measure and record full frequency spectra and sound intensity of the various noise sources and to determine the potential for noise reduction. Real-time sound intensity measurements and sound pressure level (SPL) measurements of the significant noise sources were undertaken on a fully loaded crawler in order to obtain actual maximum operational noise level conditions.

SPL measurements provide an overall sound level of the combined noise sources at the microphone position, useful when it is possible to measure one piece of equipment at a time. 1/3-octave band SPL of the CT's ventilation fans and radiator fans were measured and recorded.

Sound intensity measurements, on the other hand, provide an indication of both the sound intensity level and the direction of the sound energy flow, that is, a sound intensity measurement indicates that sound may be flowing out of or into a surface. Sound intensity measurements were taken of the major noise sources that change level with load including the diesel generator sets, the hydraulic systems, and various control room and cab surfaces. 1/3-octave band frequency sound intensity and sound level spectra were measured and recorded during a shuttle rollout [20].

The sound levels were analyzed and sound intensity mapping techniques used to determine the major noise sources on the crawler and the sound level contributions of the various noise sources. figure 20 shows a sound intensity mapping obtained for the CT. Conceptual noise control measures were then determined and presented. This resulted in the removal of the old and installation of new, custom designed and upgraded engine exhaust mufflers, and upgraded engine/pump room ventilation. The first phase was designed to reduce noise levels around the CT both on the ground and on the walkways, but a secondary benefit of the upgrades is improved air quality in the engine/pump room. Previously, the engine exhaust outlets were located directly under the CT, so operators walking under it to inspect the large trucks were exposed to both noise and diesel smoke. Along with the upgraded mufflers, the exhaust pipes were extended beyond the end of the CT, ending up in front of the radiator fan outlets (see figure 21). This greatly increased the distance between the operator and the exhaust outlet noise and diesel smoke. Using the air movement from the radiator fans, the diesel smoke is now blown out from the end of the CT rather than exhausted under the CT.

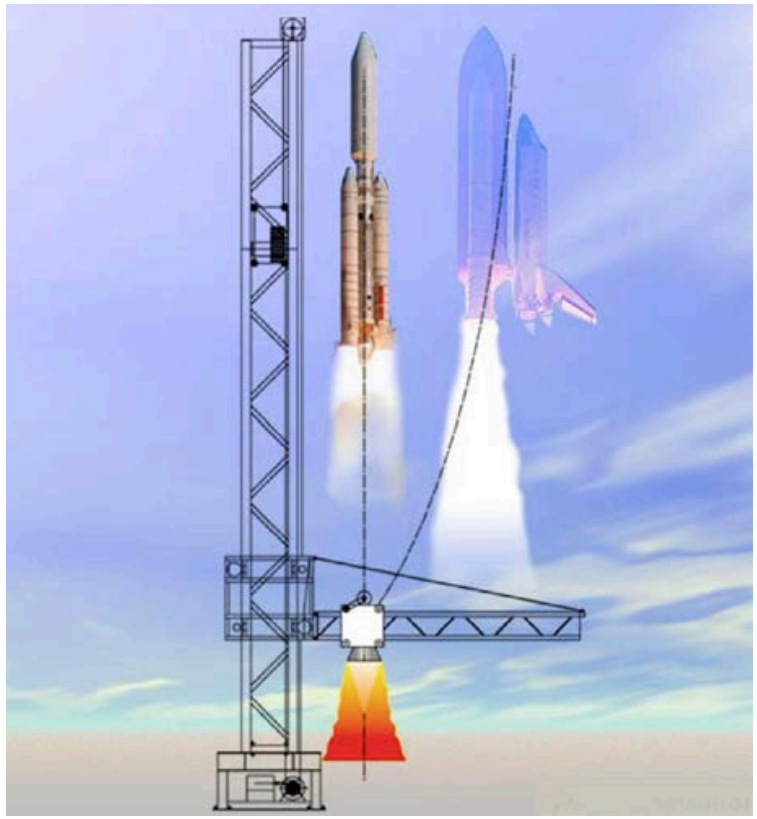

Figure 17. TSM-trajectory test capabilities.

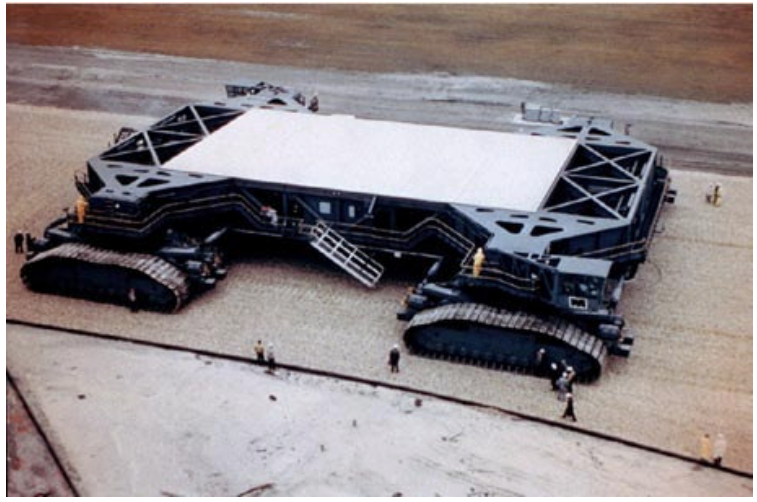

Figure 18. The crawler transporter.

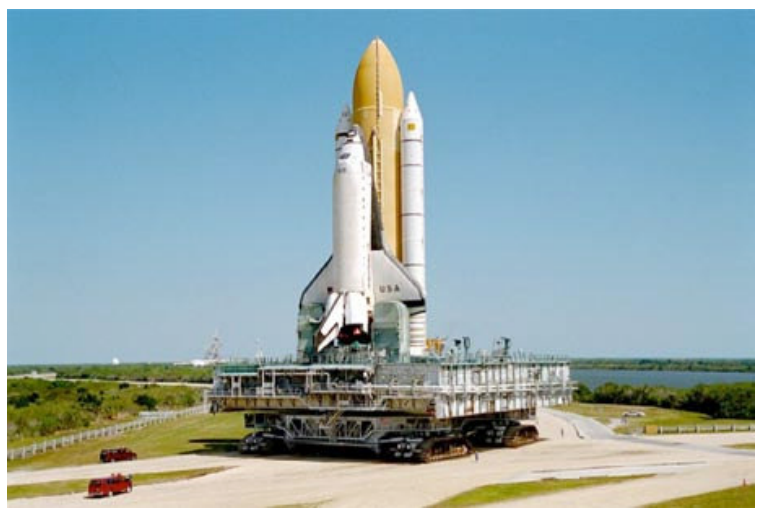

Figure 19. Crawler transporting a space shuttle. 


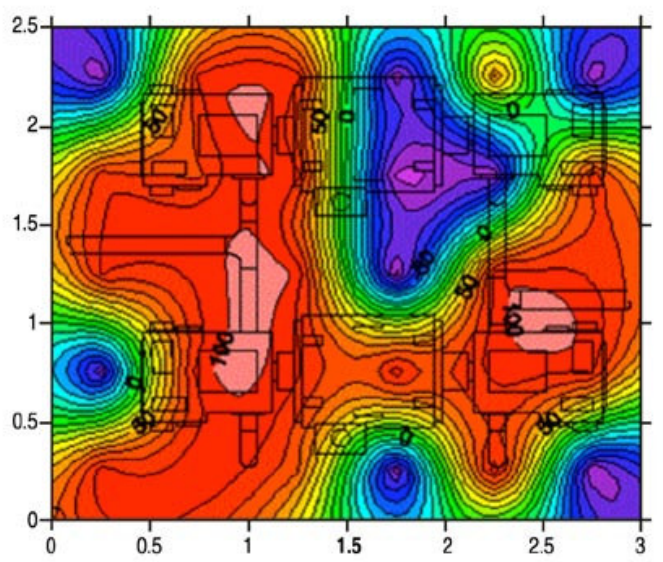

Figure 20. $400 \mathrm{~Hz}$ sound intensity contours for the CT when traveling to the pad ramp.

In the past, the ventilation air was drawn in from the sidewalls of the engine/pump room where it would first sweep across the engines before being driven down over the workers and exhausted out through twelve louvered outlets in the floor. The ventilation air is now drawn in from under the CT through twelve filtered and acoustically treated inlet hoods, thus using the coolest air available. The cool air is forced up through the floor grates, and first sweeps across the workers. It then flows across the engines to the ceiling where it is exhausted via fourteen silenced outlets.

This change in airflow direction as well as the increased volume of ventilation air allows the engine/pump room to operate with a greatly reduced temperature increase, and allows the doors to remain closed during operation. The closed doors in conjunction with the silenced floor and wall ventilation openings have significantly reduced noise levels around the CT, both on the catwalks and on the ground, enhancing operational conditions for the CT crew. Table 1 shows a summary of the noise reductions achieved after phase 1 .

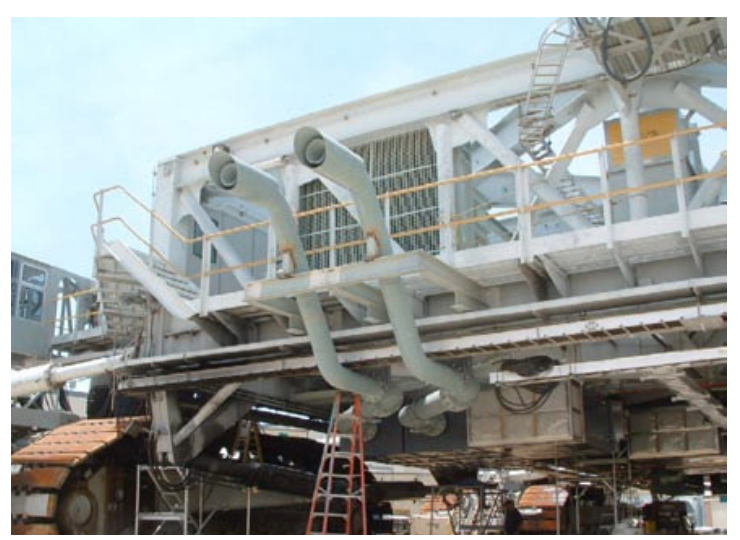

Figure 21. Exhaust pipes and upgraded mufflers.
Table 1. Noise reductions at the CT after phase 1 .

\begin{tabular}{|l|c|c|c|}
\hline Description & \multicolumn{2}{|c|}{$\begin{array}{c}\text { Measured } \\
\text { sound levels } \\
\text { (dBA) }\end{array}$} & $\begin{array}{c}\text { Reduction } \\
\text { noise } \\
\text { (dBA) }\end{array}$ \\
\cline { 2 - 3 } & Before & After & \\
\hline $\begin{array}{l}\text { CT side ventilation air exhaust } \\
\text { openings }\end{array}$ & 101 & 77 & 24 \\
\hline $\begin{array}{l}\text { CT end ventilation air exhaust } \\
\text { openings }\end{array}$ & 101 & 85 & 16 \\
\hline $\begin{array}{l}\text { Existing 6 blade ventilation air } \\
\text { intake openings }\end{array}$ & 88 & 72 & 16 \\
\hline $\begin{array}{l}\text { Existing 2 blade ventilation air } \\
\text { intake openings }\end{array}$ & 91 & 72 & 19 \\
\hline $\begin{array}{l}\text { On catwalk, engine room door } \\
\text { open and closed }\end{array}$ & 97 & 86 & 11 \\
\hline $\begin{array}{l}\text { White engines 600 rpm exhaust } \\
\text { outlet }\end{array}$ & 85 & 75 & 10 \\
\hline $\begin{array}{l}\text { White engines 900 rpm exhaust } \\
\text { outlet }\end{array}$ & 91 & 86 & 5 \\
\hline $\begin{array}{l}\text { Alco engines 900 rpm exhaust } \\
\text { outlet }\end{array}$ & 80 & 67 & 13 \\
\hline $\begin{array}{l}\text { Alco engines } 1000 \text { rpm exhaust } \\
\text { outlet }\end{array}$ & 93 & 84 & 9 \\
\hline
\end{tabular}

The second phase of the noise-control plan is to suppress the JEL (jacking, equalization, leveling) hydraulic systems noise. The hydraulic systems are all rigidly mounted on the CT's superstructure and use rigid piping except for the final connections to the hydraulic cylinders. The pump tone generated by the systems was identified as one of the major noise sources in both the control room and the driver cabs, even though the hydraulic lines do not run directly under these areas. The JEL system noise-control measures include mounting the JEL motors and pump skids on rubber isolators, the use of elastomeric pipemounting clamps to isolate the hydraulic lines from the CT's superstructure, installation of flexible hose between the pumps and the rigid hydraulic lines, and installation of in-line hydraulic silencers to reduce the pump tone.

The third phase will encompass the installation of acoustical absorption on the walls and ceilings of the engine/pump room, use of sound lock vestibules at the engine/pump room's doors, and application of an upgraded sound reduction wall between the engine/pump room and the control room. This will reduce the noise levels in the control room, and lower noise levels outside the CT due to a decrease in the reverberant sound level inside the engine/pump room. 
On the other hand, the CT consists of four double-tracked trucks, 3 meters high and 12 meters long. Each of the 8 tracks contains 57 shoes with each tread shoe weighing about $900 \mathrm{~kg}$. During CT shoe inspection/refurbishment, cracks were found in many shoes, propagating from the internal cavities below the shoe roller path and related to defects in the casting.

The cracks mostly originated in the short slot section of the shoe, on the top of the large cavity. Metallurgical examination of the shoe sections indicated that the observed cracks were due to fatigue phenomenon; attributable to and originating from subsurface casting defects at the time of manufacture several decades ago $[21,22]$. A comprehensive test, structural analysis and non-destructive examination of existing shoes and rollers were then performed to identify the failure modes, assess adequacy of metallurgical requirements, and develop structural characteristics for the procurement of new shoes. Two separate types of tests, dynamic and static were developed for the evaluation of old shoes and to provide engineering rationale for the procurement and certification of new shoes.

In addition, a NASTRAN full shoe finite element model (FEM) was developed earlier in the test program. The structural analysis was instrumental in identifying high stress zones in the shoe due to roller loads and aided in accurate placement of strain gages. Variety of sensitivity analysis has been recently performed using this analytical model to understand influence of structural, contact, and loading parameters [23].

\section{CONCLUSIONS}

It can be concluded that launching a spacecraft requires to take into account all the noise and vibration effects that can influence the success of a space mission. This article highlighted the major damages that can affect the launch pad, space vehicles, and their payloads due to the high acoustic loads and extreme conditions produced during the launching. KSC and the adjacent Cape Canaveral Air Force Station (CCAFS) are prime sites for performing vibroacoustics research because of their history as the location of most U.S. launch vehicles. Hands-on knowledge of launch pad personnel and engineers working with "real-world" environment and structures has benefited the Space Shuttle program tremendously. To obtain statistically significant data and eliminate launch-to-launch variations, hundreds of pad measurements (acoustics, vibration, strain, etc.) have been performed. Intense thermal, vibroacoustic and environmental extremes during launch have resulted in technology innovations in the area of sensors, signal data processing methods, software development, etc.

Further research results that will be obtained at KSC will enable researchers to study acoustic loads on pad structures, vehicle and ground systems, launch duct designs, acoustic mitigation techniques and structural vibration and acoustic prediction methods.

\section{ACKNOWLEDGMENTS}

Most of the research described in this article has been sponsored by The NASA John F. Kennedy Space Center (KSC). The authors extend their sincere appreciation to all NASA KSC management for their continued support and, in particular, to Mr. Roy Bridges, Jr., Astronaut and former Director, NASA KSC. Special thanks are due to Nina Ravi, for searching and selecting some of the photographs.

\section{REFERENCES}

[1] M.J. Crocker. "The Vibroacoustic Environment of Spacecraft During Launch and Flight". Sound and Vibration. Vol. $36 \mathrm{~N}^{\mathrm{o}}$ 6, pp. 5. 2002.

[2] R.N. Margasahayam and R. Caimi. "Launch Pad Vibroacoustics Research at the Kennedy Space Center". Sound and Vibration. Vol. $36 \mathrm{~N}^{\mathrm{o}}$ 6, pp. 28-33. 2002.

[3] R.H. Lyon and R.G. DeJong. "Theory and Application of Statistical Energy Analysis". Boston: Butterworth-Heinemann. Second Edition. 1995.

[4] J.T. Broch. "Mechanical Vibration and Shock Measurements". Naerum: Bruel \& Kjaer. 1984.

[5] J.T. Reason and J.J. Brand. "Motion Sickness". London: Academic Press. 1976.

[6] "Evaluation of exposure to whole-body, z-axis, vertical vibration in the frequency range 0.1 to 1.0 Hz”. ISO draft addendum to ISO 2631. 1997.

[7] R.W. McLeod and M.J. Griffin. "Effects of wholebody vibration wave from and display collimation on the performance of a complex manual control task". Aviation, Space and Environmental Medicine. Vol. $61 \mathrm{~N}^{\circ}$ 3, pp. 211-219. 1990.

[8] P.J.E. Forsyth. "The physical basis of metal fatigue". London: Blackie and Son. 1969. 
[9] W.J. Kacena and P.J. Jones. "Fatigue prediction of structures subjected to random vibration". Shock and Vibration Bulletin. Vol. 46 No 3, pp. 87-96. 1976.

[10] W.O. Hughes and M.E. McNelis. "Recent advances in vibroacoustics". Sound and Vibration. Vol. 36 $\mathrm{N}^{\mathrm{o}}$ 6, pp. 20-27. 2002.

[11] W.O. Hughes and M.E. McNelis. "Cassini/Titan IV acoustic blanket development and testing". NASA TM- 107266. Julio 1996.

[12] T.D. Scharton. "Vibration and acoustic testing of spacecraft". Sound and Vibration. Vol. 36 N $^{\mathrm{o}} 6$, pp. 14-18. 2002.

[13] "Sonic and vibration environments from ground facilities - a design manual”. NAS-11217. Marzo 1968.

[14] "Environments and test specification levels ground support equipment for space shuttle system launch complex 39". GP-1059. Kennedy Space Center. 1976.

[15] "Procedure and criteria for conducting dynamic analysis of the orbiter weather protection structure". KSC-DM-3147. Septiembre 1987.

[16] “Computation of generalized modal loads in an acoustic field defined by a distribution of correlated pressures". KSC-DM-3265. Agosto 1989.
[17] "Validation of a deterministic vibroacoustic response prediction model". NASA-TM-112649. Abril 1997.

[18] R.N. Margasahayam, R. E. Caimi and S. Hauss. "Rocket launch trajectory simulation mechanism". in Proc. ICSV9. Orlando, Florida. Julio 2002.

[19] Reported in Spaceport News/KSC. Vol. 42 N $^{\circ} 24$. Noviembre 2003.

[20] C. Faszer, R. Margasahayam and R. MacDonald. "Space Shuttle Crawler Transporter Sound Attenuation Study”. Proc. Inter-Noise. 2004.

[21] "Crawler Transporter (CT) Tread Belt Shoe - Test Data Analysis, Structural and Fatigue Analysis Summary". NASA/KSC Internal Document. Mayo 2004.

[22] K.A. Meyer, S.M. Nerolich, R.C. Burton, A.M. Gosselin and R.N. Margasahayam. "Space shuttle crawler transporter vibration analysis in support of rollout fatigue load spectra verification program". Proc. ICSV11. St. Petersburg. Julio 2004.

[23] K.A. Meyer, R.C. Burton, A.M. Gosselin and R.N. Margasahayam. "Space shuttle crawler transporter truck shoe qualification tests and analysis for return-to-flight". Proc. ICSV12, Lisbon. Julio 2005. 